no effect on either the complete response rate or the length of remission within each subgroup. Similarly, the sites of disease (nodes and lung) and the patients' ages (under 20) did not significantly influence either complete response rates or the length of remission between the prednisone and no-prednisone groups.

Although our data do not agree with those of the British study there are some major differences between the two studies. Our study was a retrospective analysis comparing groups of patients treated over different times. Most of those patients receiving prednisone were treated before 1974 or had had no mediastinal irradiation. A prospective randomised study of strictly comparable patients is always to be preferred in judging the value of a treatment, but we did evaluate the effect of patient selection by analysing each subgroup and found no significant differences in the complete response rate or length of remission between those who did and did not receive prednisone.

A possible explanation for the different findings of the British study is that good partial responses might have been converted into clinical complete responses by prednisone. Whether or not these apparent complete responses last will be known only after three to five years. The value of chemotherapy for Hodgkin's disease must be measured not only by the complete remission rate but also by the length of the remissions. Current studies indicate that about $60^{\circ}{ }_{0}$ of the patients should remain in complete remission for at least five years and probably indefinitely. ${ }^{910}$

The unusually low complete response rate of $44^{\circ}{ }_{0}$ in the British group who had no prednisone is disturbing. The rate is significantly lower than that reported by most other groups. ${ }^{9} 10$ Since the report of the British study was a preliminary one, it does not provide information on the amount of myelosuppressive drugs actually given in the two treatment groups. Their results could be explained if more mustine and procarbazine had been given to the prednisone group because of higher peripheral blood counts, which might be expected in that group.

The British study used prednisone in every cycle of their treatment programme. This may have brought out differences that are not as apparent when the steroid is used for only two cycles. But our results with a regimen without prednisone are quite comparable to those in the British patients who received prednisone in every cycle. Furthermore, most of these complete responses to MOP have produced durable remissions for at least five years. This suggests that eliminating prednisone does not reduce the efficacy of the MOPP regimen.

These studies were supported in part by grants CA-08122 and CA-05838 from the National Cancer Institute, National Institutes of Health, Bethesda, Maryland, USA.

\section{References}

1 Frei, E, et al, Cancer Research, 1966, 26, 1284.

2 DeVita, V T, et al, Annals of Internal Medicine, 1970, 73, 881

${ }^{3}$ Castellino, R A, et al, Annals of Internal Medicine, 1974, 80, 593.

4 Report from the British National Lymphoma Investigation, British Medical fournal, 1975, 3, 413.

5 Lukes, R J, et al, Cancer Research, 1966, 26, 1311.

${ }^{6}$ Kaplan E L, and Meier, P, fournal of the American Statistical Association, 1958, 53, 457.

7 Gehan, E A, Biometrika, 1965, 52, 203.

${ }^{8}$ Moore, M R, et al, Cancer, 1973, 32, 52.

9 Portlock, C S, et al, Proceedings of the American Association of Cancer Research and American Society for Clinical Oncology, 1976, 17, 248.

11 DeVita, V, et al, Proceedings of the American Association of Cancer Research and American Society for Clinical Oncology, 1976, 17, 269.

\title{
New technique for investigating bacterial flora of female periurethral area
}

\author{
W BRUMFITT, J M T HAMILTON-MILLER, M BAKHTIAR, J COOPER
}

British Medical fournal, 1976, 2, 1471-1472

\section{Summary}

The bacterial flora of the female periurethral area was studied by impression cultures taken with polystyrene sponges, the results being recorded by photographic contact printing. With this technique it is possible to observe the preferential colonisation of different areas by different organisms and to detect persistent colonisation by pathogens. In assessing the possible aetiological importance of these results, and especially in comparing them with the findings of other workers, it is essential to use correct anatomical nomenclature.

\footnotetext{
Department of Medical Microbiology, Royal Free Hospital, London NW3 2QG

W BRUMFITT, FRCP, professor

J M T HAMILTON-MILLER, MRCPATH, senior lecturer

M BAKHTIAR, MSC, research assistant

J COOPER, MB, clinical assistant
}

\section{Introduction}

The role of bacterial colonisation of the regions surrounding the female urethral meatus in the initiation of urinary tract infections has long been a source of speculation. Several attempts have been made to isolate pathogenic strains of bacteria from patients subject to relapse or reinfection by swabbing various sites within and around the vestibule, ${ }^{1-6}$ but the conclusions drawn have varied. A major reason for this may well be the lack of standardisation of both microbiological technique and anatomical nomenclature. These two factors combined constitute such a problem that it seems doubtful whether any of the reported studies could be repeated by other workers. We therefore draw attention to the official definitions (according to anatomy texts) of the terms "vestibule" (the whole area inside the labia minora), "introitus" (synonymous with the vaginal orifice), and "perineum" (the area between the thighs from the coccyx to the pubis). In gynaecology and obstetrics, however, the perineum is commonly referred to as the region between the posterior commissure of the labia majora and the anus.

The confusion that has arisen through imprecise nomenclature includes "introital" used apparently synonymously with "vaginal vestibular"' (we have been unable to find a definition of the term "vaginal vestibule"), "vaginal,"5 and "periurethral." " Even as simple a word as periurethral has been defined in more than one way. (Bailey et $a l^{4}$ termed as 
periurethral a swab taken inside the urethral meatus.) Microbiologically, swabbing techniques are unsatisfactory, as they sample only small and ill-defined areas, give little if any idea of quantification of a mixed flora, and may even constitute a health hazard by transferring bacteria to previously uninfected areas.

There has recently been renewed interest in the ecology of human normal flora, and it now seems likely that the presence of certain bacterial strains may actually be beneficial to the host, particularly on the skin ${ }^{7}$ and in the mouth. ${ }^{8}$ This approach is clearly attractive also with regard to urinary tract infections. It seems to us that a technique that allows an accurate degree of location of the components of a mixed flora in a carefully defined area, the results of which can be recorded easily and permanently, might be helpful in respect of the flora of the vestibule. We describe such a technique.

\section{Patients and methods}

Patients attending the renal polyclinic at this hospital were investigated for colonisation of the vestibule.

$S w a b s$-Polystyrene foam cylindrical sponges $(3 \mathrm{~cm}$ long, $2.5 \mathrm{~cm}$ diameter) of the same pattern as those used as wadding in tablet bottles were obtained from Syntex Ltd, Swindon. They were autoclaved at $115^{\circ} \mathrm{C}$ for 20 minutes in screw-capped jars and discarded after use.

Media-MacConkey, cystine-lactose-electrolyte-deficient (CLED) agar, and blood agar plates were used, having first been dried in an incubator at $37 \mathrm{C}$.

Microbiological techniques-Impression cultures were taken before collecting a midstream specimen of urine, so that neither contamination by urine nor cleansing of the area had taken place. The patient was placed in the dorsal position with the thighs widely apart, the labia majora being well separated by a nurse. A sponge was applied to the area between the urethral orifice and the vagina (which we term the "urethrovaginal bridge"), care being taken to avoid contact with the labia minora. The sponge was then applied in turn to the surfaces of CLED, MacConkey, and blood agar plates, its original orientation being maintained and indicated on each plate. Immediately afterwards the same area was rubbed with a cotton-wool swab moistened with sterile saline. The swab was also inoculated on to fresh plates of the above three media and spread with a wire loop in the usual way. Plates were incubated overnight at $37^{\circ} \mathrm{C}$.

Recording results - Contact prints were made of the two transparent plates, the plates themselves being used as photographic negatives. In this technique the plate is laid on sensitive paper (Ilford 3M) and collimated light shone through it from an enlarger, an exposure of 12 seconds being used for CLED plates and 25 seconds for MacConkey plates. The paper is then developed and fixed in the usual way. After contact printing, representatives of the different colonies present on the plates were picked off with a straight wire and identified by conventional methods. ${ }^{9}$ The cultures on blood agar were inspected to see if they contained any colonies absent from the two selective media.

\section{Results and discussion}

Over five months 70 impression cultures were taken from 34 patients. Our results with the technique (detailed comparative microbiological and clinical results will be reported later) have convinced us of its potential usefulness in studying the role of skin colonisation by bacteria in the aetiology of recurrent urinary tract infections. The ability to observe preferential colonisation of different areas by different organisms (see figure) is perhaps the greatest advantage of the impression culture over conventional swabbing techniques.

Contact printing usually gave as good reproduction of plates as did conventional photography (see figure). It is also much quicker and cheaper than conventional photography and may be done with a minimum knowledge of photographic techniques. The only disadvantage occurs when repeat prints are required of a plate that has been discarded. In this case a negative would have to be made from the original contact print with a possible loss in quality.

The variety of bacteria isolated from the cotton-wool swabs was similar to that from the sponges. The organisms, however,

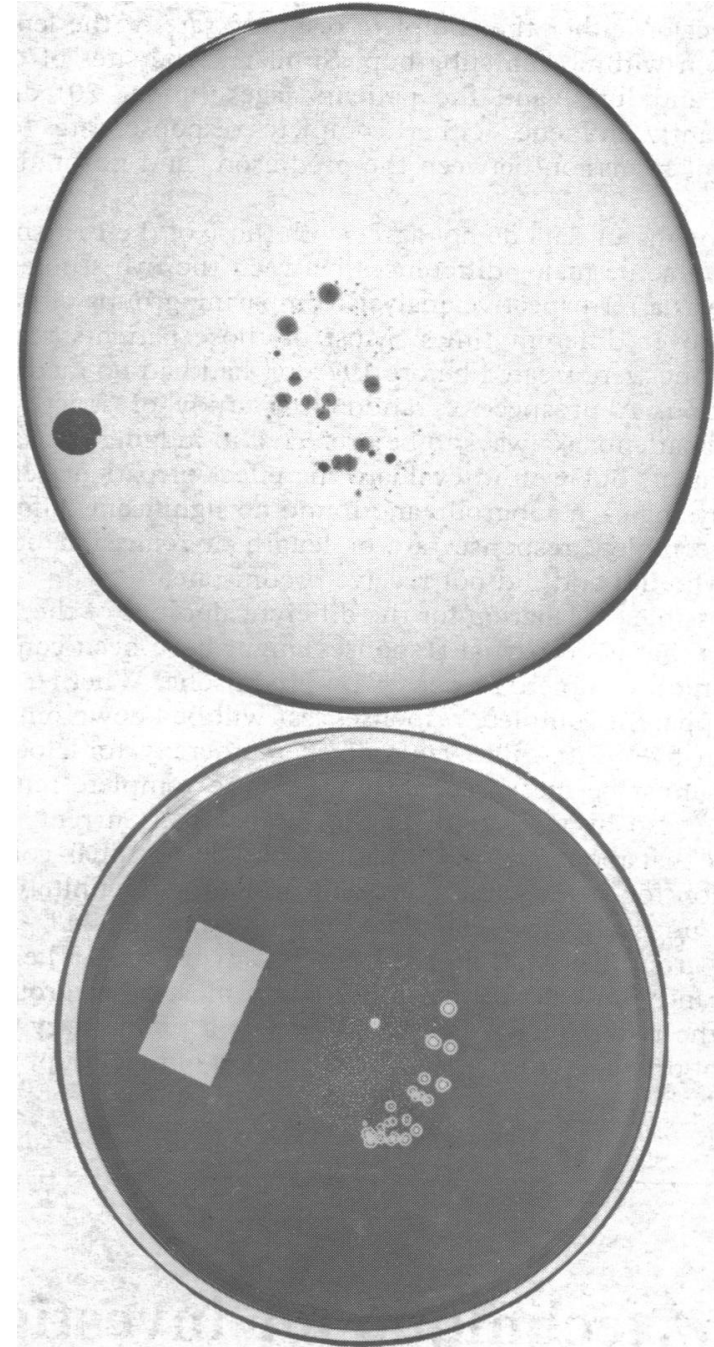

Impression swabs from two patients cultured on CLED agar. Top: Photograph. Bottom: Contact print. Marker indicates edge nearest urethral meatus. Large colonies subsequently identified as Escherichia coli, and small colonies as Streptococcus faecalis.

could not be quantified as well as by examination of the impression cultures, and it was, of course, impossible to define the way in which bacteria were distributed on the urethrovaginal bridge.

Using this technique we are now examining bacteria on the urethrovaginal bridge at regular intervals. This method enables persistent colonisation by pathogens to be detected and their relation to recurrent infections determined. The method will also be valuable in defining the differences in flora between controls with no history of infection or asymptomatic bacteriuria and patients with proved recurrent infections. Thus the importance of such colonisation in the aetiology of recurrent infection will become clear.

We are grateful to Dr S J D Brooks for valuable discussion.

\section{References}

1 O'Grady, F W, et al, Lancet, 1970, 2, 1208.

2 Stamey, T A, et al, California Medicine, 1971, 115, 1.

${ }^{3}$ Marsh, F P, Murray, M, and Panchamia, P, British fournal of Urology, 1972, 44, 368.

${ }^{4}$ Bailey, R R, et al, Lancet, 1973, 2, 275.

${ }^{5}$ Ekins, J B, and Cox, C E, fournal of Urology, 1974, 111, 88

6 Cattell, W R, et al, British Medical fournal, 1974, 4, 136.

7 Selwyn, S, British Fournal of Dermatology, 1975, 93, 487.

${ }^{8}$ Donoghue, H D, and Tyler, J E, Archives of Oral Biology, 1975, 20, 381.

9 Cowan, S T, and Steel, K J, Manual for the Identification of Medical Bacteria, 2nd edn. London, Cambridge University Press, 1974. 